\title{
OUSAR DIZER A “VERDADE” SOBRE O PRÓPRIO GÊNERO (APESAR DA CIS-HETERONORMA): QUESTÕES TECNOLÓGICAS E NORMATIVAS PARA DIZER-A-VERDADE-SOBRE-SI DE SUJEITOS TRANSGÊNEROS
}

\section{Dare to say the "truth" about the own gender (in spite of cis-heteronormativity): technological and normative issues to tell-the-truth-about-yourself of transgender subjects}

\author{
SÉrgio Rodrigo da Silva Ferreira ${ }^{1}$ \\ ${ }^{1}$ Universidade Federal da Bahia. Salvador, BA, Brasil. \\ E-mail: sergiorodrigosf@gmail.com
}

\section{RESUMO}

O que custa dizer a verdade? Neste artigo discutimos o processo de se afirmar como sujeito transgênero tendo em vista as possibilidades tecnológicas (médicas, de escrita, de comunicação) e normativas de cada período histórico e cultural. Ao considerar o dizer-averdade-sobre-si, é preciso levar em conta os modos como o regime de verdade atua sobre os sujeitos, ora afirmando sobre suas subjetividades por saberes avalizados, ora pelos modos como individualmente faz ressoar tais verdades sobre suas experiências de vida, os movendo a inventar modos de vivenciá-la, reafirmando ou subvertendo tecnologias e discursos. Na primeira parte, discutimos o atravessamento das tecnologias na ação de dizer-a-verdade-sobre-si de sujeitos trans e, na segunda, a influência da normatividade de gênero nos regimes de verdade, arguindo favoravelmente ao uso do termo "transgênero" por centrar-se nas relações poder a partir da categoria gênero.

Palavras-chave: subjetividade; gênero; transgeneridade; escrita de si; tecnologias digitais.

\section{ABSTRACT}

What does it cost to tell the truth? In this article we discuss the process of asserting oneself as a transgender subject considering the technological (medical, writing, communication) and normative possibilities of each historical and cultural period. When considering the tellingthe-truth-about-yourself, it is necessary to take into account the ways in which the regime of truth acts on the subjects, sometimes affirming about their subjectivities by endorsed knowledge, sometimes by the ways in which they individually resonate such truths about their life experiences, moving them to invent ways of experiencing it, reaffirming or subverting technologies and discourses. In the first part, we discuss the crossing of technologies in the action of telling the truth about yourself by trans subjects and, in the second part, the influence of gender normativity in truth regimes, arguing favorably to the use of the term "transgender" for focusing on the gendered power relations.

KEYWORDS: subjectivity; gender; transgenderity; self-writing; digital technologies. v. 23, n. 44, p. 203-221, set.dez., 2021. doi: https:// doi.org/10.1590/2596$304 \times 20212344$ srsf 


\section{PARA INÍCIO DE CONVERSA, DOIS CASOS}

No dia 24 de junho de 2018, L. postou em seu perfil do Facebook a seguinte mensagem (Figura 1):

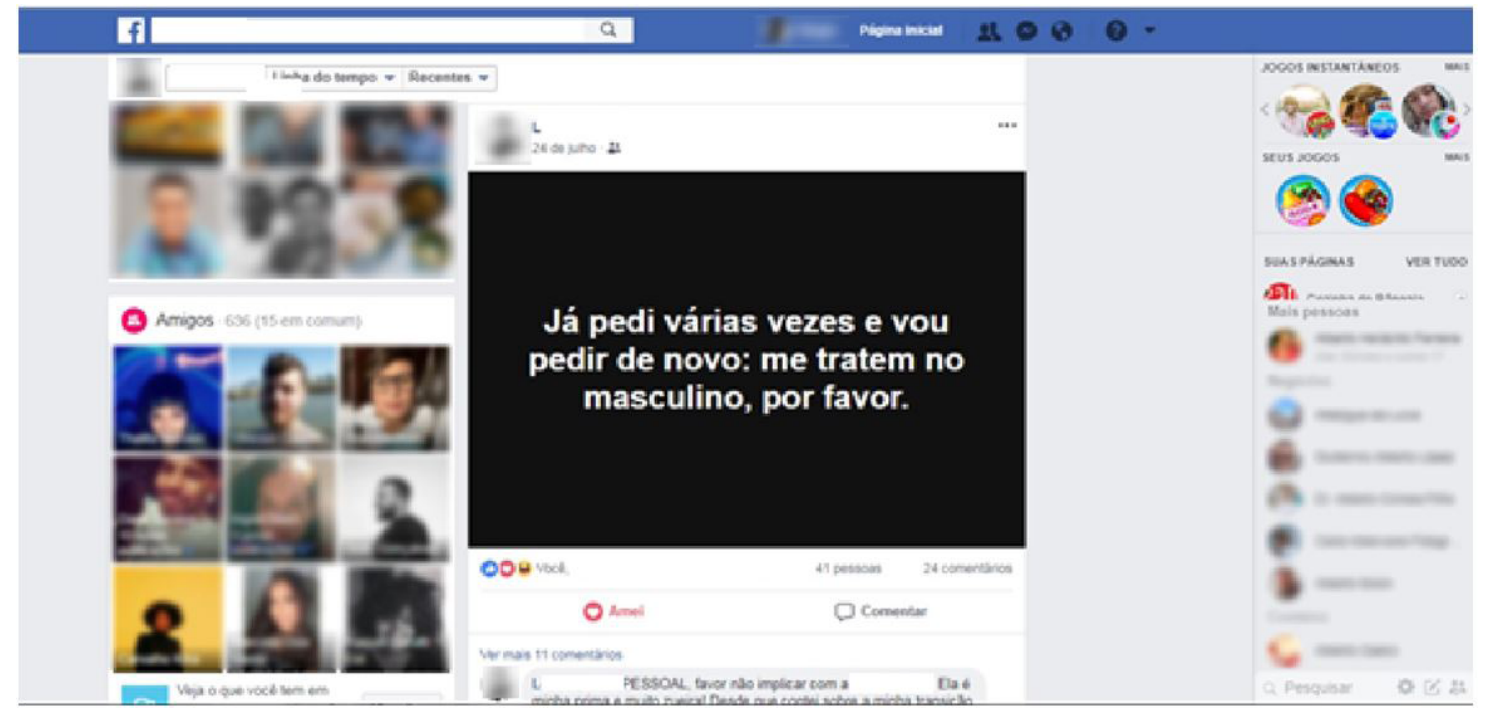

Figura 1 - Impressão da tela da postagem feita por L., no dia 24 de julho de 2018. Fonte: Facebook.

L. ${ }^{1}$ é um homem trans branco, sudestino, de 26 anos, que trabalha como cozinheiro. Na postagem (Figura 1), ele se mostra na necessidade de dizer sua verdade de identificação de gênero e cobrar dos outros uma postura de respeito a essa identidade ao tratá-lo pelo gênero no qual se expressa. Nesse caso específico, é um rapaz trans que está a se colocar publicamente como masculino e está a fazê-lo há pouco tempo, ainda lidando com os conflitos dessa autoafirmação. $\mathrm{O}$ ato de dizer "já pedi várias vezes e vou pedir de novo" carrega parte desse conflito e ainda a abertura de uma possibilidade de diálogo, seguido pela locução adverbial "por favor", como quem pede com gentileza.

Ao mesmo tempo em que vemos uma pessoa que se quer respeitada como identidade de gênero masculina, percebe-se um conflito implícito com outros usuários ao se colocar nessa condição. $O$ pedido expõe o aspecto de construção social do gênero e, mais ainda, de negociações públicas desse gênero e o conflito para impor-se. Estão implícitos um público que não aceitaria sua condição e um embate pela afirmação.

Ao lermos os comentários da postagem, logo vemos alguns desses sujeitos e esses processos de negociação, com suas alianças e seus embates. Alguns comentários elogiavam fisicamente o rapaz ("Gostoso", "Lindo") ou destacavam a afetividade dentro daquela identidade de gênero ("Guri da minha vida "); outros reforçavam a mensagem e pediam respeito ("Respeitem esse homem, porra!!!", "N entendi o 'haha' na reação mas tudo bem... MeninO sim", "Pq ve não aproveita esse post pra excluir gente preconceituosa? É um prato cheio."). Houve ainda comentários de quem não apoiava a autodeclaração e

1 Por serem pessoas vulnerabilizadas, preferimos suprimir os nomes dos interlocutores citados neste texto. Os casos aqui elencados fazem parte de um projeto de pesquisa maior que visa debater a escrita de si de homens trans na plataforma de rede social Facebook. A participação na pesquisa foi consentida pelos interlocutores aqui mencionados. 
até zombava dela ("Que menino linda....kkkkkkkkkkkk"; "Aiiii eu não consigo!!! Vc é a XXXX² da minha vida! Mas te amo de qualquer jeito, seja feliz. $\vee^{\prime}$ ). Nesses casos as respostas do homem trans foram as de se autoafirmar como homem na maioria dos comentários e pedir para que se acostumassem com a sua nova identidade.

Entretanto, houve um comentário que, apesar de recusar a identificação trans do sujeito (" $V c e ́$ menina") e ter reação contrária ("Vcé uma imbecil") - seguida de uma discussão entre os comentadores -, teve em resposta um pedido de não consideração por parte de L.: "PESSOAL, favor não implicar com a XXXX3. Ela é minha prima e muito zueira! Desde que contei sobre a minha transição ela me dá o maior apoio e eu amo ela demais! ७ $\vee$ ”. Essa afirmação mostra que as interações e declarações nesses espaços são atravessadas por uma série de relações e afetos, por outras espacialidades, temporariedades e sociabilidades, para além da presente exclusivamente na plataforma de rede social.

Outro caso é de M., também homem trans, de 25 anos, estudante de psicologia, que publicou uma postagem também no Facebook na qual afirmava que, apesar de ser algo muito pessoal, era preciso expor o caso: um áudio de sua mãe no qual ela o confronta por usar um nome masculino. $\mathrm{O}$ áudio faz referência a uma cena da telenovela da rede Globo de Televisão, "A Força do Querer", que foi ao ar entre abril e outubro de 2017, na qual é retratada a descoberta, transição e aceitação de um personagem transmasculino, Ivan, interpretado pela atriz cisgênera Carol Duarte (Figura 2).

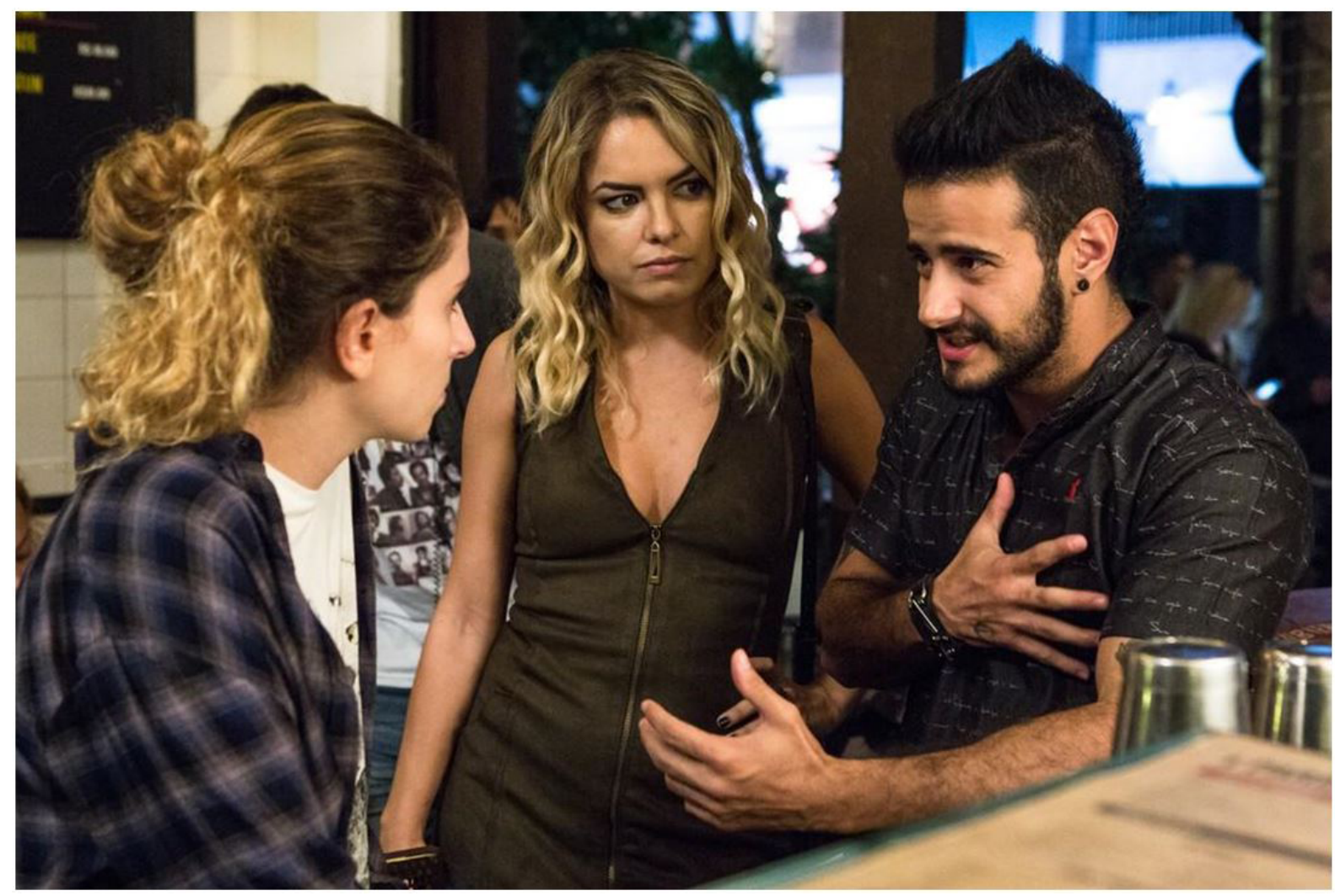

Figura 2 - Frame da cena da novela "A força do querer" em que Tarso Brant, dizendo chamar-se Tereza, explica para a personagem Ivana o que é transexualidade. Fonte: Gshow.

2 Nome usado anteriormente à transição do gênero foi suprimido.

3 Nome suprimido. 
Aqui é preciso fazer uma rápida menção à referida cena ${ }^{4}$. Nela, a ainda Ivana (personagem que posteriormente se descobriria e viveria sua identidade transmasculina) se encontra pela primeira vez com um homem trans e se espanta com aquela possibilidade de existência. $O$ homem trans em questão é Tarso Brant, que por conta dessa aparição ganhou maior projeção nacional. Na cena, em um barzinho, uma amiga apresenta um homem para Ivana que ao cumprimentá-la se apresenta como Tereza: "oi, Ivana, prazer, Tereza”. Ivana acha que ele está de brincadeira e o repreende dizendo que não quer saber de "gracinha" "Olha, eu sei que é estranho, mas meu nome é Tereza mesmo", ele retruca. Como Ivana continua descrente, ele continua: "essa barba aqui confunde, né? Mas foi o nome que minha mãe me deu, daí eu não tive coragem de trocar”. "E que mãe dá nome para um menino de Tereza?”, questiona Ivana. E Tarso/Tereza responde: "é uma longa história, mas, olha, eu nasci menina, em um corpo feminino, só que eu não me sentia menina, entende?”. Ivana continua incrédula, até que sua amiga surge e confirma a história: "ele é trans, nasceu em corpo de mulher, mas não se identificava... Você nunca ouviu falar nele? Coloca na internet para você ver: Tereza Brant, B-R-A-N-T. Tem toda história dele lá”. A amiga pede para Tereza mostrar uma foto antiga sua e ele entrega uma foto impressa anterior à transição. A cena termina com Ivana olhando em choque a foto de Tereza criança e a imagem de Tarso adulto.

Ao compartilhar o áudio de sua mãe (provavelmente enviado por Whatsapp), M. descreve a cena como uma abordagem sensacionalista da mídia e de uma representatividade que não seria correta, dando uma visibilidade que trata a questão trans como "atração de circo" ao optar por apresentar "um homem com um nome feminino”. O autor da postagem pede para que todos ouçam o áudio e compartilhem para que as pessoas saibam o que "acontece na vida real". Transcrevo o áudio aqui:

...e mais uma coisa para lhe dizer: eu tenho filha, eu não tenho filho. Outra coisa para lhe dizer também: você deveria me respeitar também como eu lhe respeito. Eu estava vendo aqui na televisão, esses casos que estão acontecendo aí, isso para mim não é normal, você está entendendo? Eu bato na mesma tecla que Deus fez o homem e fez a mulher, fez o homem para mulher e a mulher pro homem. Então, assim, eu estava vendo aqui, me chamaram para ver minha novela, que tem um caso que é igual ao seu, que disse que apareceu um trans dizendo que o nome dela é Tereza e ia continuar sendo Tereza, porque foi o nome que a mãe dela deu para ela. Que ela estava em um corpo de homem, que estava como homem, mas que o nome ia continuar Tereza. Que por sinal não é um caso de fição, é um caso verídico, só fez uma participação na novela. Aí eu olhei e disse assim: 'engraçado, né? E minha filh a não me respeita, querendo que eu chame ela pelo nome de homem'. Essa daí respeitou a mãe e respeita até hoje, que zela até pelo nome que a mãe deu e não quer tirar, continua sendo chamada de Tereza. Se você pesquisar, você vai ver quem é Tereza. Aliás, você já deve conhecer, né? O que todo mundo fala é isso, sua falta de respeito comigo, você não me respeita, entendeu? Porque eu gerei uma menina, criei até quase 20 anos, para com essa idade dizer para mim que é um homem e querer que eu chame pelo nome de homem e não vê que minha situação é delicada e difícil para fazer isso. (...) Você não tem vergonha na cara de falar isso para mim? Falar de respeito? Todas as pessoas aqui me entendem, menos você. Olha o exemplo que eu te dei da Tereza! Vai pesquisar lá sobre a Tereza se você não conhece. Tereza é um trans, como diz você. E respeita a mãe dela (gritando)! Ou dele, eu não sei. E você não me respeita, nunca, eu não pari homem, eu pari uma menina. E outra coisa: nunca você vai conseguir tirar isso de mim (gritando), que você quer que eu te chame pelo nome de homem. Você tem que me respeitar, que todo mundo fala isso para mim: 'ela primeiro deveria lhe respeitar, ela poderia estar exigindo isso de outras pessoas, dos amigos dela, de quem fosse chegando depois de você, não de você não, ela não tem que the pedir isso'. Tá? Lhe respeitar eu respeito até demais, the respeito, não faço pouco caso de você, the amo do mesmo jeito, mas você quer que eu te chame pelo nome de um homem? Isso é querer demais. Eu gerei uma menina no

4 A cena está disponível em https://globoplay.globo.com/v/6038130/. Acesso em 03 de mar. 2021. 
meu ventre, procure entender isso. Eu gerei uma menina no meu ventre, pari, criei até 20 anos, para que com 20 anos dizer que é homem e você querer que eu the chame pelo nome de homem. Ponha-se no meu lugar. Qualquer pessoa entende isso, não falto com respeito com você não. A opção que você fez foi essa, não é isso, não é o que você quer? Mas também me respeite. E não poder, nem conseguir the chamar pelo nome de homem, isso não é questão de não the respeitar não, você que não está me respeitando, procure analisar. Ou melhor, dê esse áudio aí para alguém escutar para ver se alguém não vai me entender, entender meu lado de mãe, é muito fácil para seus amiguinhos que vieram depois de mim lhe chamar pelo nome de homem, é muito fácil para quem não lhe criou, que não acompanhou seu crescimento lhe chamar pelo nome de homem, mas para mim é difícil, eu sou a mãe, para mim é difícil. Eu te criei, você entendeu bem, eu gerei uma menina dentro de mim, para mim isso é difícil, não falto com respeito com você não, nunca faltei com respeito, a opção foi sua. Eu não tenho mais nada o que fazer, a vida é sua, eu não posso passar por cima disso. Agora eu te falo: me respeite! Me respeite! Me respeite como uma mãe! (gritando).

Gostaríamos de destacar dois aspectos da fala da mãe de M. Um primeiro é uma tentativa de reiteração de uma normativa de identidade de gênero que não só é baseada em um alinhamento entre o sexo enquanto biológico e o gênero enquanto cultural numa perspectiva cis-heterossexual, mas em um respeito ao gênero que foi "dado" pela mãe. O respeito à identidade de gênero diz sobre uma espécie de capital dado, ou cedido, a partir de uma adequação à normalidade da performatividade de gênero esperada a partir de um ideal normativo.

Outro aspecto é o de a própria fala trazer a existência de duas distintas camadas de entendimentos do que é normal, uma da mãe e dos seus, e outra do filho e dos seus. São duas dimensões de normalidade em conflito, em que curiosamente a categoria significante mobilizada é um entendimento de "respeito". A mãe não se sente respeitada como figura materna que gerou e criou uma filha em que o sexo e o gênero eram femininos e se sente violada ao ter que tratar o filho no gênero que ele expressa, que, por outro lado, se sente desrespeitado justamente pela mãe não o tratar como gostaria. É um conflito discursivo que não se resolve sem que pelo menos um dos lados ceda. Aqui é um exemplo muito explícito tanto daquilo que Amara Moira (2018) vai chamar de guerra travada contra qualquer outra narrativa de gênero que não contemple a cisgeneridade, quanto onde Michel Foucault (1985) vai apontar como a disputa pelo estabelecimento do que é verdadeiro nas relações de poder tem o formato da guerra.

Obviamente que o conflito não é proporcional tendo em vista que a própria fala da mãe evoca atores como Deus, valores familiares tradicionais, televisão, mainstream, vizinhos, ou seja, toda uma história colonial e capitalista, e os dispositivos de poder que normalizam o gênero e a sexualidade em nossa sociedade. Mãe e filho são a capilaridade de uma relação de poder em que verdades sobre $o$ gênero são o próprio exercício da guerra capitalista-colonialista sobre seus corpos.

Esse caso é especialmente rico para demonstrar a análise que faremos mobilizados ao redor da categoria da "norma" aos modos foucaultianos, mas também a maneira de Keguro Macharia (2018) que ao analisar a legislação e a política quenianas para a população queer do país debruçou sobre a norma sexual. Ele argumenta que "precisamos entender os direitos das minorias sexuais em relação ao direito da maioria sexual", uma vez que "qualquer tentativa de argumentar em favor do primeiro sem considerar o último corre o risco de perder sua constituição mútua" (MACHARIA, 2018, p. 111-112).

A descrição desses dois casos nos ajuda a lançar a questão deste artigo: o que significa um homem trans falar sobre si na plataforma de rede social on-line do Facebook? E mais, em que aspecto a produção de subjetividade e produção de comum podem se aliar, no ambiente digital, para criar 
corpos políticos engajados em produzir aberturas no entendimento de gênero nas fissuras do biopoder baseado na cis-heteronorma?

Fazemos essas perguntas, guiados pelo clássico texto dos estudos trans estadunidenses de Sandy Stone (2015), O Império Contra-ataca: um manifesto pós-transexual, no qual, ao analisar as primeiras autobiografias de mulheres trans publicadas no suporte livro impresso, a autora debruça-se sobre o que chama de "contos morais" e "mitos fundantes", quando se procura dizer a "verdade" sobre o gênero (a própria autora usa as aspas).

Do mesmo modo, situaremos os elementos que compõem as ações que visam produzir efeitos de verdade sobre si numa perspectiva de gênero. Assim como as escritas de si produzidas por pessoas transgêneras nos livros analisados por Stone, queremos pensar modos de cartografar escritas pessoais em plataformas de redes sociais, ao considerar sua inserção em contextos tecnológicos distintos e os atravessamentos dessas tecnologias e das normas nesse relatar-se a si mesmo.

\section{DIZER A “VERDADE” SOBRE O PRÓPRIO GÊNERO}

Stone (2015) parte do pressuposto de que a imagem e o real se definem a si mesmos por meio das práticas e das inscrições, que, do ponto de vista técnico, estão subordinadas às ideias que as governam. Nessa perspectiva, as subjetividades se expressariam por inscrição, ou seja, a expressão/tradução das heterogeneidades do ser/estar em materialidades inteligíveis.

Ao analisar as autobiografias de mulheres trans, a autora questiona qual o tipo de sujeito que se constrói nesses escritos ${ }^{5}$. Ao pensar relações de gênero que se arquitetam ao descrever características associadas aos sujeitos no processo de redesignação sexual, ficam evidentes narrativas que se baseiam em um “corte” em suas vivências, uma descontinuidade. É uma narrativa na qual a intervenção médica cria uma ideia de um antes e de um depois.

Essas narrativas mostram a passagem de um homem absoluto para uma mulher absoluta, não existindo um território intermediário. Para Stone há uma cumplicidade, portanto, com uma performatividade de gênero do homem branco ocidental, um reforço do modelo binário e polarizado da identificação sexual. Há a produção de duas vozes diferentes, como uma necessidade de negar as "potencialidades da mescla", uma ativa atuação de preservar "uma identidade de gênero 'pura" (p. 45), havendo um homem essencial antes e uma mulher essencial depois que essas mulheres trans encarnariam.

A suposta identidade profunda repousa sobre um lugar físico, nas "glândulas germinais". A virilidade está no pênis e no escroto, e desejos e comportamentos estariam ligados a eles. Há nesses relatos uma áurea mística: ao remover cirurgicamente os genitais masculinos, a nova mulher surge como que magicamente incorporando características associadas ao feminino, reproduzindo uma visão masculina estereotipada do que seria uma mulher, o que inclui carência, desejo sexual por homens, fraqueza, vontade por usar vestido e maquiagem e "desmaio delicado diante da presença de sangue"

\footnotetext{
5 As narrativas que são destacadas como objeto de análise por Stone são Man Into Woman: the first sex change, que narra a história de Lili Elbe, a qual é parcialmente autobiográfica, escrita por Niels Hoyer, a mais antiga que existe, de 1933; I Changed My Sex!, de Hedy Jo Star, de 1955, a primeira totalmente autobiográfica; Conundrum, de Jan Morris, de 1974; Canary, de Canary Conn, de 1977. A autora também fala a respeito dos "Arquivos Obrigatórios Transexuais", que eram coleções não catalogadas, nas quais mulheres trans costumavam guardar artigos de jornais e trechos de diários pessoais sobre comportamentos de gênero considerados "inapropriados", dos quais possuía alguns exemplares.
} 
(p. 46). Passa-se de um polo do gênero ao outro; se existe um espaço intermediário no contínuo da identidade de gênero, ele é invisibilizado (STONE, 2015).

Ao imbricar essas narrativas com a literatura médico-psicológica, Stone coloca o problema da avaliação da performance de gênero pelos profissionais da saúde, todos homens cisgêneros, que avaliavam as candidatas a cirurgias de redesignação sexual, por meio de entrevistas de seleção nas clínicas americanas de disforia de gênero em um período em que:

as interações se produzem cada vez mais por meio de escritos, conferências por computador, e meios
eletrônicos, e não mediante contato pessoal, e quando, consequentemente, a subjetividade individual
pode constituir-se por meio da inscrição mais do que por associação pessoal, seguem existindo momentos
de "verdade natural" corpórea que não se podem evitar (STONE, 2015, p. 47, tradução nossa).

Nessas entrevistas as candidatas à cirurgia eram avaliadas segundo sua capacidade de performar o gênero escolhido. Ao confrontar a literatura dos saberes institucionalizados sobre transexualidade na época, os critérios usados como referência na escolha das candidatas eram de uma definição de gênero "aculturada" e "acordada", evidenciando a materialidade de um aparato de produção do gênero na sua representação (STONE, 2015).

As mulheres trans, nesses contextos, estavam jogando o jogo da narrativa médico-psicológica, uma vez que as candidatas a cirurgias de redesignação sexual eram avaliadas pela sua capacidade de se enquadrar e representar uma caricatura do gênero a que pretendiam ser, sem qualquer contradição nessa imagem. É aqui que Stone nos faz uma potente provocação: quem, efetivamente, está narrando a história de quem, nesses textos? Como essas narradoras diferenciavam entre a história que contavam e a que escutavam sobre si? Os critérios para diagnóstico da disforia de gênero eram um obstáculo para que aquelas mulheres tivessem acesso à tão almejada cirurgia de redesignação sexual e, desse modo, entendiam e performavam o que o sistema médico lhes solicitava: a sensação de habitar o corpo “errado" (STONE, 2015).

A produção narrativa de si nesses casos apostava na construção de um sujeito que se constitui, levando em conta um regime de verdade sobre pessoas trans estrategicamente calcado na introjeção daquilo que se identifica como pessoa transexual a partir dos protocolos de diagnóstico das clínicas médicas que faziam cirurgias experimentais de redesignação sexual, que, por sua vez, possuíam uma visão bastante estreita de gênero e, mais especificamente, do que deveriam ser uma mulher e um homem.

No Brasil, Amara Moira (2018) também analisa as primeiras autobiografias de pessoas trans lançadas em livro, especialmente na década de 1980, embora aqui não leve em conta o repertório médico-psicológico e, sim, a estrutura editorial de publicação desses relatos e a influência na sua apresentação, focando nas formas como eram lidas. Ao tratar sobre A Queda para o alto (publicado em 1982, pela editora Vozes), obra escrita por Anderson Herzer, a primeira narrativa de uma pessoa trans (ainda que não se autodenomine dessa forma), Moira expõe a violência em citar o nome de registro de Anderson e traz evidências de que todo o processo editorial operou numa neutralização da experiência transgênera ao apagar o prenome, ao impor ao autor um gênero que não lhe era condizente e ao conceber explicações patologizantes de sua identidade. É nesse aspecto que aqueles que lançaram o livro escancaram "o caráter compulsório da cisgeneridade, a guerra travada contra qualquer outra narrativa de gênero” (MOIRA, 2018, on-line). Assim, editores e aqueles que prefaciam e criticam a obra 
estão na verdade buscando reafirmar a norma (não muito diferentemente dos guardas que violentavam Anderson, quando este esteve preso, e lhe chamavam de "machão sem bolas"; há em ambos os casos um descrédito da identidade de gênero por um viés biologizante).

Diferentemente de Anderson Herzer, João W. Nery (1984) foi o primeiro homem trans autodeclarado como tal em seu texto, mas há aqui diferentes vivências nas transmasculinidades. Se Herzer escreve como alguém que vive na perspectiva da pobreza e escreve como detento que sofre a violência do cárcere, Nery escreve como "filho da classe média carioca", "psicólogo de formação" e com "convívio desde a infância com importantes intelectuais", o que lhe garantiu acesso às discussões mais recentes sobre transexualidade feitas pelas ciências psi, bem como às cirurgias clandestinas como "uma das primeiras cobaias" para modificação do seu corpo para que pudesse ser lido como masculino (MOIRA, 2018, on-line).

Essa outra vivência aparece na narrativa de Nery na marcação de uma transgeneridade masculina e também ao afirmar que foi "nascido mulher", sugerindo que a designação de gênero que recebemos ao nascer não seja necessariamente aquela em que nos reconhecemos e ainda por descrever-se como "nascido homem, aprisionado num corpo de mulher" (MOIRA, 2018, on-line), utilizando-se do mesmo discurso mapeado nas mulheres trans estadunidenses por Sandy Stone: o do "corpo equivocado", bastante comum nos protocolos médicos acerca da definição da transexualidade na segunda metade do século XX. As narrativas trans expressas pelos seus próprios sujeitos iam se inventando, porém

ainda muito contaminadas pela perspectiva cisgênera, o que se percebe em "corpo de mulher" (ideia hoje tão criticada pelo movimento trans e pelo feminista), na ideia de nascer no corpo errado (forma de responsabilizar o corpo pelas violências que sofremos, não a sociedade), mas também na de "transexual feminino" que Nery (...) usa para referir-se aos homens trans. (MOIRA, 2018, on-line)

A obra de Nery foi republicada em edição revista e atualizada em 2011, com o título Viagem Solitária: memórias de um transexual trinta anos depois (NERY, 2011), no qual já consta o termo "transexual masculino". É valido lembrar ainda que ambas as publicações, tanto a de Herzer quanto a de Nery, ocorreram no início da década 1980, por editoras que se constituíam nesse período como fontes de narrativas consideradas de resistência ao regime civil militar da época (1964-1985), havendo assim um viés de liberação dos costumes nessas apostas editoriais (CHAVES, 2018).

Esse processo de normalizar a experiência cisgênera nos relatos trans tanto pelo processo editorial quanto pelos profissionais dos saberes médicos-psis vão ao encontro do que Sandy Stone (2015) afirma ter uma grande similitude com o discurso colonial: uma fascinação com o exótico, a negação da subjetividade, a falta (ou limitação, ou diferença) de acesso ao discurso dominante e a reabilitação da espécie, no sentido de, ao ser lida, a experiência trans na perspectiva cis-heteronormativa é apresentada como anormalidade para assim ser reconduzida a uma readequação à norma (ao invés de alargar a norma).

E é no corpo trans, "campo de batalha" das experiências de gênero vividas, território "de inscrição cultural altamente disputado" por ser "uma máquina semântica para a produção de categorias ideais", que vemos projetados acordos temporais que surgem dos debates do presente sobre práticas e crenças de saberes institucionalizados (STONE, 2015, p. 54-55) sobre gênero, sexualidade e direito ao corpo. 
Essa batalha é que aumenta os custos para se dizer a verdade sobre si; é preciso ter coragem para dizer a sua verdade.

Sobre a questão, Riki Anne Wilchins (2015) fica às voltas com a pergunta: o que custa dizer a verdade? Ela cita um trecho do texto de mesmo nome em que Foucault faz perguntas sobre a necessidade de falar sobre si e essas questões são disparadoras para que ela pense essa coragem da verdade para pessoas trans. O trecho é este:

Como é possível que o sujeito humano se converta a si mesmo em um objeto de conhecimento possível? Por quais formas de racionalidade, por quais necessidades históricas e a que preço? Minha pergunta é a seguinte: quanto custa para o sujeito ser capaz de dizer a verdade sobre si mesmo?” (FOUCAULT apud WILCHINS, 2015, p. 108, tradução nossa)

Wilchins, entre algumas narrativas, vai refazendo a questão de Foucault, como quem tenta encontrar uma resposta: o que custa dizer a verdade, o que custa dizer a verdade...? Dentro dessa problemática, ela narra quando começou a ter para si que a sua altura tornou-se um problema aos 26 anos de idade, sendo que anteriormente isso nunca havia sido uma questão. Ela descreve vários momentos em que é interpelada sobre sua altura por desconhecidos em variados espaços. Isso acontece porque Wilchins, que é trans, passa a ser lida como mulher e como mulher, inserida no contexto cultural de seu país, os Estados Unidos da América, ela não deveria ter uma estatura tão alta. Esse incômodo de Wilchins faz com que ela passe a utilizar estratégias para "esconder" sua altura: usar certas roupas, certos calçados, andar curvada. Sua história e a de outras pessoas vão provocá-la a responder à questão: "o que custa dizer a verdade?”.

Ela narra que as pessoas que vivem em dissidência sexual supervivenciam a necessidade de se fazer de si mesmas objeto de conhecimento possível, serem interpretadas e consideradas. Estando sob o regime de gênero, cujo objetivo é o de regular os significados e castigar quem os transgrida, os sujeitos obrigam-se a situar-se como um lugar de verdade a ser dominado, o reconhecimento de si vem de fora, do olhar de outras pessoas sobre si, expresso ou subentendido. É preciso saber como os outros te veem para se ver e os significados que adquirem o corpo (WILCHINS, 2015).

Wilchins (2015) compara o corpo ao documento de identidade mostrado para averiguar-se se está em conformidade, seja "quando entrar em uma estação de metrô, solicitar trabalho, perguntar a polícia por alguma localidade, utilizar um banheiro feminino ou passar sozinha a noite com um grupo de homens" (p. 109, tradução nossa). O sujeito está o tempo todo a evocar sua imagem mental de si, a verdade de seu aspecto, muitas vezes sentindo vergonha de seus defeitos e orgulho de suas características atrativas. E, nesse sentido, importa menos como realmente se parece e mais como se sente em relação a esse corpo a partir da consciência do olhar do outro, que o faz experimentar uma sensação de perturbação e vulnerabilidade, uma vez que esse corpo-documento está a ser mostrado, questionado e julgado. Na perspectiva do gênero, seu status e sua legitimidade estão sempre dependentes e determinados por esse olhar externo causa de um mal-estar, uma desorientação no descompasso entre a sensação de ser e a (des)aprovação do outro (WILCHINS, 2015).

A leitura do corpo é culturalmente relativa, dependendo do contexto em que se situe (WILCHINS, 2015). Cada época considera sua própria composição de características corporais como se fossem "naturais" e eternas. Mas os corpos, tal como qualquer produto cultural, passam por fases, períodos 
e modas. Até mesmo, no campo das masculinidades, a identidade cultural "pirocão" (big dick), por exemplo, seria uma categoria instável:

mas sempre é o maior, não? Não necessariamente. Thomas Laquer assinala que os antigos gregos, de quem herdamos grande parte da nossa estética, consideravam masculinos e atrativos os pênis pequenos. As pirocas grandes eram consideradas como algo animalesco, e com frequência o alvo (desculpa) ${ }^{6}$ de piadas públicas. Os homens com pirocas grandes aprenderam a sentir vergonha delas e começaram a 'trucá-las', como faz qualquer delicada drag queen. Um amigo trans, que recentemente tinha regressado de uma viagem à Grécia, me contou o quão cômodo se sentiu ali. Em todas as partes, todas as estátuas e pinturas tinham pirocas pequenas e masculinas, exatamente como a sua (WILCHINS, 2015, p. 112, tradução nossa).

Wilchins (2015) declara que o corpo é uma situação, ao afirmar que para entender os corpos e o olhar sobre eles devemos construir o que nossos corpos podem significar e qual o aspecto que eles podem ter.É no significado expresso no corpo da cultura que encontramos a verdade. Quase tudo sobre o corpo embasado numa cultura se descobre na comparação entre a coleção de significados armazenados na linguagem comum sobre ele: "bonito, gordo, sensível, masculino, baixo, de pele clara, enrugado, feminino, largo, elegante, feio, esportivo, deformado, magro, corpulento, peitudo, velho, delicado" (WILCHINS, 2015, p. 114). O sistema de gênero tenta impor aos corpos significados monolíticos. Se a percepção de si mesmo coincide bastante com o olhar cultural do que ele deveria significar e se se encontra confortável com esses significados, então a verdade não te custa muito. "Mas para o resto de nós, sem dúvida, o custo é muito maior" (p. 114).

Podemos associar o que Wilchins descreve como o olhar cultural sobre os corpos à introjeção do regime de verdade sobre a subjetividade dos sujeitos. Como veremos mais à frente, o regime de verdade é o conjunto de regras que distingue o verdadeiro do falso e é distinto em cada sociedade. Pelas imagens que a autora evoca, o regime de verdade de um povo e sua cultura carregam em si expectativas de modos de ser e performatizar a partir de certas diferenciações sexuais, o gênero. E, muitas vezes, somos chamados a prestar contas sobre nossas características, nossos modos de ser e nossas escolhas a partir desse regime. Não estar em conformidade com o regime de verdade sobre o gênero nos submete a processos, muitos deles violentos, no sentido de se fazer adequar-se à norma. No caso de pessoas trans, lhes são negados uma série de direitos, além de estarem submetidas às violências físicas e verbais, e ao risco de morte. É esse o custo da verdade que exige coragem e estratégias para sobrevivência.

Foucault (2011) dedica um curso no Collége de France, seu último, especificamente sobre a questão da coragem da verdade, em 1984. O estudo desenvolvido e apresentado nessa ocasião dizia respeito à fala franca (parresía) como uma das formas de dizer a verdade. Um dos interesses do filósofo naquele momento enfocava as chamadas formas aletúrgicas, que são aquelas que dizem respeito à produção da verdade e aos modos como ela se manifesta. Ainda que, em seu estudo, Foucault trate sobre a questão na Antiguidade, ele lança aspectos importantes para pensarmos o dizer-a-verdadesobre-si atualmente. Interessa-nos construir, a partir das condições das formas, $\mathrm{o}$ ato de o sujeito dizer a verdade no sentido de representar a si mesmo, de modo que essa verdade seja reconhecida como

6 Wilchins faz aqui uma piada sobre a condição de branquitude ("blank"), que funciona também em português ("alvo" como "objeto ao qual se mira" ou como "o que é predominantemente claro, branco"). 
tal pelos outros, uma vez que no "ato de dizer a verdade, o indivíduo se constitui e é constituído pelos outros como sujeito que pronuncia um discurso de verdade” (p. 4).

Nessa relação do sujeito com a verdade, o recorte é o daquele que é capaz de dizer sobre si mesmo por formas culturalmente reconhecidas. Se na Antiguidade era muito importante dizer a verdade sobre si mesmo, o que dizer sobre a cultura nas plataformas de redes sociais, em que cada vez mais somos levados a condições de constantemente estarmos falando sobre nós? É aqui que procuramos dialogar com Foucault, ao constituir uma análise do dizer-a-verdade-sobre-si-mesmo no presente, ao pensar essa cultura do si contemporânea, em que se desenvolvem e se reproduzem jogos on-line de práticas de si. Se o dizer-a-verdade-sobre-si, na cultura antiga, a partir da leitura foucaultiana, era uma atividade conjunta, com um outro, praticada a dois, com um outro necessariamente presente, como podemos pensar esse aspecto nesse ambiente específico em que o sujeito está em um contexto de ambiência digital? Onde a interlocução é difusa e múltipla? No qual esse outro é mais ou menos determinado e mais ou menos controlado (pelo sujeito)?

Esse outro, negativado na leitura de Wilchins, é, na leitura de Foucault, necessário no processo de autoconhecimento. A relação com ele, entretanto, não é uma relação qualquer; passa por um processo de entender que ele possui um estatuto variado, mas que na relação com aquele que diz-a-verdadesobre-si (parresiasta) precisa ter uma certa qualificação. Ainda no sentido de delimitar essa fala franca específica, Foucault afirma que essa verdade característica sobre si possui como singularidade ser uma verdade de como o sujeito se pensa e na qual quem participa entra no jogo. É ainda uma verdade que coloca o sujeito que se afirma em um certo risco em relação a esse outro, "risco de ferir o outro, de irritá-lo, de deixá-lo com raiva e de suscitar da sua parte algumas condutas que podem ir até a mais extrema violência” (FOUCAULT, 2011, p. 12). Há poucas verdades a serem afirmadas sobre si que causem mais risco de violência extrema na atual sociedade brasileira do que as que dizem respeito às dissidências sexuais e às desobediências de gênero.

Foucault resume assim o escopo da fala franca sobre si, o que necessariamente lhe interessa em seu estudo sobre a coragem da verdade:

é preciso que, no ato de verdade, haja: primeiro, manifestação de um vínculo fundamental entre a verdade
dita e o pensamento de quem a disse; [segundo], questionamento do vínculo entre os dois interlocutores
(o que diz a verdade e aquele a quem essa verdade é endereçada). (...) ela implica uma certa forma de
coragem, coragem cuja forma mínima consiste em que o parresiasta se arrisque a desfazer, a deslindar
essa relação com o outro que tornou possível precisamente seu discurso. (FOUCAULT, 2011, p. 12)

É assim que, ao compor a verdade sobre si, o sujeito está em relação ao outro, e ao mesmo tempo atravessado por outras relações de poder de uma determinada composição de sociedade de determinado tempo histórico, que chamaremos de regime de verdade.

O regime de verdade está a atuar em duas frentes sobre o sujeito: uma como a verdade estabelecida sobre ele e outra no processo de produção de verdades sobre si, nas quais o sujeito faz ressoar algumas verdades ou as nega. Além disso, o meio de expressão carrega seus próprios dispositivos e atravessa significativamente esse dizer-a-verdade-sobre-si.

É por isso que, quando pensamos nos casos levantados até aqui, somos levados a questionar: quais são as condições que diferem o post de L. e M. das narrativas de Anderson Herzer e João W. Nery? 
Fazendo ressoar e parafraseando a pergunta de Stone: que sujeitos estão a se construir nessas narrativas enredadas e digitalizadas? Quais sujeitos e quais verdades falam ao mesmo tempo que o sujeito que está a dizer-a-verdade-sobre-si? A seguir debateremos o papel das normas nesse processo de pensar e estruturar o discurso sobre o próprio gênero.

\section{DIZER-SE “TRANSGÊNERO” E A DISPUTA PELO NORMAL}

É muito importante demarcar que entendemos a norma não como um poder regulador transcendente que invariavelmente é aplicada por um ente externo para conformar a uma certa ordem, como o modelo jurídico da lei. Nós a compreendemos aos modos de Georges Canguilhem (2009) e Michel Foucault (2008): a norma, de modo imanente, é produzida pelo próprio movimento da vida.

O normal, enquanto aquele(a) ou aquilo que está de acordo com a norma, no modelo biológico supracitado, se distingue em duas modalidades: a primeira refere-se a uma dimensão fixa e vinculativa a uma ideia de "normalidade" que parece poder ser aplicada apenas mecanicamente a um dado anterior; e uma segunda que se refere à dinâmica criativa de uma "normatividade" que potencialmente dá lugar à plasticidade e até ao desafio das normas estabelecidas, à inventividade de novas normas e formas de vida (CANGUILHEM, 2009). A força das normas deve, portanto, ser entendida como a eficiência imanente de sua ação, que produz as condições para sua própria realização.

Naquele primeiro sentido, a norma aparece como uma operação corretiva por meio da conformação a um modelo. Aqui a norma é normativa. É nesse sentido que dizemos que a cisgeneridade e a heterossexualidade são normativas, ao estabelecer modelos de modos de ser enquanto identidade e desejo, a partir de uma leitura binária do sexo (entendimento constituinte da materialidade do corpo). Essa norma de um modo de ser dada por uma cultura, em um determinado território, em um determinado contexto histórico, a partir de determinadas relações de saber/poder, é o que chamamos de gênero. São comportamentos, estéticas, modos de agir e desejar, formas que os corpos devem tomar e papéis sociais que são constantemente reificados para que possamos diferenciar os sujeitos. $O$ gênero enquanto norma, portanto, nos fala da imanência em suas ações reificadoras ao criar as condições para sua própria realização.

Esse processo normativo de reificação do gênero acontece como uma normalização disciplinar, nesse primeiro caso, isso é,

em primeiro colocar um modelo, um modelo ótimo que é construído em função de certo resultado, e a operação de normalização disciplinar consiste em procurar tornar as pessoas, os gestos, os atos, conformes a esse modelo, sendo normal precisamente quem é capaz de se conformar a essa norma e o anormal quem não é capaz. (FOUCAULT, 2008, p. 75)

Se o normal é, portanto, apenas o que está de acordo com a norma, o anormal é o que resiste a ela. Para que haja uma normalização, antes de haver um normal e um anormal há uma norma (FOUCAULT, 2008). A identificação do normal e do anormal nos faz perceber que há diferentes curvas de normalidade que funcionam pela operação de normalização. Essa operação se estrutura pela distribuição de normalidade de modo que uma normalidade funcione em relação a outra.

É por certa relação de poder que algumas dessas normalidades são consideradas mais favoráveis que outras e vão servir de norma. À vista disso, Foucault argumenta que a "norma está em jogo no 
interior das normalidades diferenciais” (2008, p. 83). É assim que a normalização estabelece um normal e a norma se deduz dele, se fixa e desempenha um papel regulatório.

O caso que trouxemos no início deste artigo é bastante significativo dessa dimensão relacional do normal e sua força operativa nas possibilidades de ser e agir no mundo. A mãe de $\mathrm{M}$. se recusa a chamá-lo pelo nome que condiz com sua identidade de gênero partindo de um princípio de normalidade no qual, pela cisgeneridade compulsória, a mãe nomeia a pessoa que foi lida como filha e é normal que essa pessoa se mantenha se chamando dessa forma para o resto da vida. Porém, $M$. declara-se não como uma mulher, mas como um homem, e como homem é normal que possua um nome masculino. Além disso, é normal no seu ciclo social de pessoas sensíveis às causas LGBTQIA+ isso acontecer. Há, portanto, duas curvas de normalidade distintas acontecendo sobre a mesma questão e elas estão em guerra.

Vemos homens trans buscarem em suas postagens no Facebook desnaturalizar a masculinidade cisgênera e normalizar as transmasculinidades em seus aspectos constitutivos. Quando esses homens estão afirmando que são homens "de verdade", mesmo sem um pênis de carne fixado ao corpo, mesmo sem serem violentos, mesmo com um corpo construído com tecnologias sexuais, mesmo passando (ou não) por transição, mesmo tendo que juridicamente retificar prenome e sexo nos documentos de identificação, e mesmo engravidando, repetem e repetem que "isso é normal”, "tem que ser normal”, afastando-se da ideia de estranho, anormal.

A mobilização de sujeitos que por muito tempo foram considerados anormais, ou estranhos (queerness), tem-se organizado ao redor de pautas de insatisfação com o regime de verdade sobre o normal normal das identificações de gênero em geral, seja do ponto de vista social, quanto do comportamental (WARNER, 2004). É nesse sentido que o questionamento à normalidade das normas de gênero é fundamental, pois são elas que baseiam o ataque ataque às pessoas queer e transgêneras.

Etimologicamente, Georges Canguilhem vai dizer que a base latina de norma que quer dizer "esquadro" e de normalis que quer dizer "perpendicular" expõem os principais aspectos da norma e do normal já nas origens das palavras. "Uma norma, uma regra, é aquilo que serve para retificar, pôr de pé, endireitar" e "normalizar é impor uma exigência a uma existência, a um dado, cuja variedade e disparidade se apresentam, em relação à exigência, como um indeterminado hostil, mais ainda que estranho" (CANGUILHEM, 2009, p. 109). Ou seja, a própria origem etimológica das palavras carrega um princípio geométrico de endireitar, de enquadrar, o que está torto, errado.

Aqui é importante demarcar a função da norma como forma de ação do poder agindo tanto como ação repressora, mas, principalmente, como estímulo e produção para a constituição do indivíduo moderno. Elizabeth Stephens (2014), a partir de Foucault, vai afirmar que a normalização produz sujeitos não simplesmente movendo-os em direção a uma norma, tornando-os mais normais, mas medindo as lacunas e diferenças pelas quais eles se desviam dessa norma. $\mathrm{O}$ que se pretende com a norma é que ela sirva como um ideal que nunca pode ser incorporado, mas em torno do qual podem ser traçadas distâncias minuciosamente de diferenciação.

Do ponto de vista do gênero e da sexualidade, é no trabalho do biológo e sexólogo Alfred Kinsey que primeiro surge o conceito de "sujeito normal”, no final dos anos 1940, mas é John Money que duas décadas depois privilegia o "normal” para discutir papéis e redesignação de gênero como uma forma de parafilia em si (STEPHENS, 2014). Na normatividade biológica, que conduz muitas das ideias sobre 
gênero e sexualidade, "o 'normal' é ontologicamente relacional, descrevendo não uma coisa fixa, mas uma orientação de uma coisa em relação à outra” (STEPHENS, 2014, online).

\section{LIMITES DO TERMO “TRANSGÊNERO”}

Lucas Platero Méndez (2014) faz um levantamento de como a construção das terminologias, e, logo, saberes, sobre a população trans passa por longos períodos de patologização das suas identidades vistas como anomalias e perversões, portanto anormalidades. É importante ressaltar que o desenvolvimento das terminologias é resultado de um determinado contexto social e histórico e que nesses períodos diferentes construções coexistiam.

Platero vai pontuar que no Iluminismo, no século XVIII, é que o pensamento científico moderno passou a ditar as verdades sobre os sexos, diferenciando-os, e é durante o século XIX e XX que os conceitos de normalidade e perversão passaram a ser categorias operacionalizadas para tratar de gênero e sexualidade, sendo que "neste contexto histórico se produz um grande salto pelo qual 'normal' já não significa 'o mais frequente', mas, também, o desejável” (MÉNDEZ, 2014, p. 91, tradução nossa).

Em 1877, Richard Von Krafft-Ebing publica Psychopathia Sexualis, compêndio com classificação de transtornos sexuais. Nele o "homossexualismo" era tido como um transtorno de gênero que era adquirido e congênito. Elementos da transexualidade eram entendidos como uma gradação mais avançada dos transtornos do "homossexualismo". Especificamente o que hoje entenderíamos como algo similar às transmasculinidades era nomeada por Krafft-Ebing como "ginandria” (MÉNDEZ, 2014). Esse é um exemplo do que aconteceu por muito tempo no entendimento das identidades trans e de toda expressão de sexualidade que se alijava das relações heterossexuais, reprodutivas e coitocêntricas, que eram demonstradas como transtorno emocional ou físico. De modo geral, a transexualidade era compreendida como uma forma extrema da homossexualidade (MÉNDEZ, 2014).

O pioneiro na defesa dos homossexuais, Magnus Hirschfeld, publica, em 1923, na Alemanha, o texto médico Die intersexuelle Konstitution ("A constituição intersexual") no qual propõe a categoria sexual "terceiro sexo" ou "estados sexuais intermediários" que englobava transexuais ("travestidos"), homossexuais, hermafroditas (intersexuais) e andróginos. Esse terceiro sexo não era um estado patologizante, mas uma variação natural da sexualidade humana motivada pela diferença de níveis de hormônios sexuais.

Não era a primeira vez que se propunha a ideia de um terceiro sexo. Karl Heinrich Ulrichs no Inclusa (1863) fala a respeito dos uranistas, possuidores de um terceiro sexo (alusão a um mito presente n'O Banquete de Platão), pessoas cujas almas masculinas habitavam corpos femininos e vice-versa. Sendo uma característica do ser que era herdada, não aprendida, não havia razões para castigá-lo. A explicação de ordem biológica despenalizava, dessa forma, os comportamentos sexuais e de gênero (Méndez, 2014). Paul Preciado tem resgatado a terminologia "uranista" para referir-se às pessoas trans; ele discorre sobre esse assunto em um texto lançado recentemente intitulado "Um apartamento em Urano" (PRECIADO, 2018).

Nesse caminho, David Caldwell, sexólogo, nos anos 1940 cunhou o termo transexual como conhecido hoje e afirmava que a transexualidade era uma predisposição genética combinada com 
infância disfuncional que causava imaturidade mental. Dessa forma, Caldwell corresponsabilizava familiares e seus entornos pela "psicopatia” referida (MÉNDEZ, 2014).

Ainda que se fizessem as cirurgias de redesignação sexual desde a década de 1920, foi na década de 1950 que Christine Jorgensen deu visibilidade à transexualidade e à possibilidade de transitar com êxito de um sexo a outro, com uma intensa presença nos meios de comunicação estadunidenses e europeus falando sobre seu processo, gerando um imaginário positivo sobre modificação corporal (MÉNDEZ, 2014). Algo similar aconteceu no Brasil com a modelo, atriz e apresentadora Roberta Close, que nos anos de 1980 pautou a mídia nacional, ganhando o título de vedete do Carnaval Carioca (1984) e sendo capa da revista Playboy, mesmo que recorrentemente fosse apontada como homem (JESUS, 2018).

O psicanalista estadunidense Robert Stoller ficou conhecido por sua teoria influente sobre a origem das transexualidades. As transexualidades masculinas, diferente das femininas, que seriam causadas pelo contato excessivo com a mãe e escasso com o pai, "provinham de avôs e avós que não valorizavam o feminino, cujas filhas (e mães da seguinte geração) desejaram ser homens, que não prestaram atenção suficiente a suas filhas e que foram tratadas como meninos, buscando atenção dos pais" (MÉNDEZ, 2014, p. 95). Por sua vez, o endocrinologista Harry Benjamin popularizaria o termo "transexual" em sua obra The transsexual phenomenon (O fenômeno transexual), de 1966, na qual propõe uma escala de sete pontos para classificar formas de "travestismo" e transexualidade (MÉNDEZ, 2014).

A Síndrome da Disforia de Gênero foi proposta por Norman Fisk, em 1973, e tratava a transexualidade como "transtorno" da identidade de gênero. Suas definições foram bastante utilizadas no contexto psiquiátrico para dizer quem era o "transexual verdadeiro" e quem não era. Os sujeitos no contexto do diagnóstico clínico tinham que ter uma trajetória e características determinadas (geralmente baseadas no horror ao sexo biológico e ao gênero ligado a ele efusivamente expresso) e que culminava necessariamente com a cirurgia genital. Chegou aos manuais que até recentemente (ou ainda hoje, em alguns lugares) consideravam a transexualidade um transtorno (MÉNDEZ, 2014).

Fazemos aqui uma ressalva, a partir de Dean Spalde (2000), que levanta os aspectos de uma economia política capitalista para a conformação às normas de gênero. Ele vai destacar que teóricas e teóricos transfeministas e queer têm privilegiado demasiadamente uma explicação das normas de gênero a partir dos discursos médicos patologizantes (como os apresentados até aqui) e não levam em conta as implicações de ações econômicas especialmente em se tratando dos sujeitos em nãoconformidade de gênero.

Spalde se preocupa em apresentar como os sistemas de assistência social e trabalho são usados para regular o gênero das pessoas mais pobres. $\mathrm{O}$ autor quer avançar nessa análise em relação às pessoas que não estão em conformidade com a norma de gênero, uma vez que essas análises, em alguma medida, já são realizadas por pesquisas de cunho feministas, especialmente com mulheres cisgêneras. Os sistemas de assistência pública, por exemplo, operaram através de entendimentos moralistas da sexualidade e da estrutura familiar para forçar os receptores a obedecer às noções sexistas e heterossexistas de feminilidade e maternidade, tais como noções supremacistas brancas de maternidade e pureza racial, e representações de mulheres negras como hipersexualizadas, preguiçosas e moralmente livres. A vigilância cotidiana das pessoas com baixos rendimentos por meio de sistemas de regras rígidas e punitivos usados nos serviços sociais criam um contexto altamente regulado para a expressão de gênero, 
sexualidade e estrutura familiar de mulheres de baixa renda que frequentemente dependem desses sistemas para sair de relacionamentos economicamente dependentes com homens (SPALDE, 2000).

Tais fatos em análise de conjecturas estruturais corroboram com a afirmação de que os modelos de cidadania e as hierarquias de gênero e raça na economia podem operar para dominar prioritariamente a vida das pessoas de baixa renda e afetam diretamente a capacidade de todas as pessoas de determinar e expressar seu gênero, sexualidade e desejo reprodutivo (SPALDE, 2000). Spalde disserta que, entretanto, poucos estudos vão centrar sua análise, entretanto, nessa esfera da crítica à economia capitalista para examinar como a regulamentação de gênero das pessoas em situação de pobreza se aplica àqueles que enfrentam mais diretamente as consequências de uma economia de gênero binária coercitiva, aqueles que transgridem as normas básicas desse binarismo de gênero (SPALDE, 2000).

Tradicionalmente, mesmo as organizações de lésbicas, gays e bissexuais (LGB) marginalizavam as questões de pessoas de baixa renda e racializadas, e focavam suas agendas políticas em reconhecimento familiar para populações LGB brancas e com recursos financeiros. Pessoas que necessitam de uma crítica à estrutura econômica que leve em conta uma análise feminista, anticapitalista e antirracista são, de modo geral, sub-representadas (SPALDE, 2000).

Enquanto isso, aqueles que estão em não conformidade com as normas de gênero, como as pessoas trans, não têm acesso às oportunidades econômicas e educacionais por conta de ações transfóbicas graves e persistentes, e sentem mais acentuadamente a regulação de gênero da economia. Entre os obstáculos que essas pessoas passam estão o abuso e o assédio em suas casas por conta de sua expressão de gênero, que muitas vezes resultam em expulsão; impossibilidade de acesso a políticas públicas e ações assistenciais por essas serem estruturalmente baseados em sistemas binários de diferenciação sexual; dificuldade de acesso ao sistema educacional no qual sofrem grandes violências que as levam ou a desistir ou a serem expulsas; discriminação severa no mercado de trabalho; sem educação e trabalho, muitas vezes, acabam envolvidas com o sistema de justiça criminal, onde são submetidas à extrema violência e assédio; dificuldade de acesso aos sistemas de saúde e a tecnologias médicas que são proibitivamente caras para muitas delas (SPALDE, 2000).

É tendo todas as negações e dificuldades de acesso que devemos entender a importância dos movimentos emergentes de autodeterminação de gênero especialmente para esses sujeitos que enfrentam na pele as manifestações da transfobia e do racismo institucionalizados, suportando ao mesmo tempo o peso das desigualdades do capitalismo enquanto lutam contra sistemas coercitivos de gênero. É preciso reconhecer que a autodeterminação de gênero e sexual não será significativa se não resistir a um sistema econômico capitalista inerentemente violento e hierárquico que fundamenta seu controle sobre os trabalhadores e os pobres em entendimentos opressivos de raça, sexo e gênero, habilidade e nacionalidade. Abordar os danos da cis-heteronorma começa pelo entendimento das "experiências daqueles que enfrentam a interseção de múltiplas opressões, centralizando na análise que essa interseccionalidade promove e pensar concretamente sobre quais estratégias um movimento dedicado a esses princípios se envolveria" (SPALDE, 2000, p. 220, tradução nossa).

O rápido percurso que fizemos com Méndez evidencia como o próprio nomear-se e entenderse como pessoas trans foi definido pelos saberes médicos e psicológicos bastante ligados à ideia de anormalidade, transtorno, patologia, potencializados por segregações de classe e raça políticas, econômicas, capitalistas, como nos alerta Spalde. Só quando esses sujeitos passam a poder nomear-se 
é que formas não patologizadas ganham força. Ao apropriar-se estrategicamente dos nomes que lhes foram dados, as identidades de pessoas trans passam de diagnóstico de sujeitos com transtorno, com disforia de gênero, para agenciamentos próprios e autonomia sobre suas autoidentificações. $O$ conceito de "trans" hoje, por exemplo, é usado em castelhano para substituir o "transexual” sem fazer a distinção daquelas pessoas transexuais pré-operadas ou pós-operadas, ainda que essa distinção importe em alguns contextos (MÉNDEZ, 2014).

No contexto latino-americano o termo "transgênero" passou a ser utilizado para pessoas que não querem necessariamente fazer uma modificação corporal. De influência anglo-saxã, ele busca evitar a distinção frente à transição e cirurgia. É preciso referir-se a Virginia Prince, ativista trans estadunidense que adota o termo para distinguir-se das transexuais e encontrar-se em algum lugar entre a transexualidade e a prática crossdresser, lutando para romper com a percepção social que associava o "travestismo" à homossexualidade ou à excitação sexual (MÉNDEZ, 2014). Essa origem do termo "transgênero" em Price é um pouco superestimada e teria se popularizado com uma diversidade de fontes e usos (WILLIAMS, 2014).

Tanto Lucas Platero Méndez como Cristan Williams vão destacar o trabalho de Leslie Feinberg Transgender liberation: a movement whose time has come ("Liberação transgênero: um movimento cujo tempo chegou") como um texto fundamental para a consolidação do termo e do uso de "transgênero". Nesse texto de Feinberg,

transgênero se convertia em um espaço de alianças para aquelas pessoas que são marginalizadas por serem diferentes das normas sociais sobre gênero e sexualidade. Possibilitava um lugar de reconhecimento e luta para aqueles que estavam à margem (...) tratava de romper com a patologização da sexualidade não normativa e gerar um movimento transformador. (Méndez, 2014, p. 97, tradução nossa)

No mesmo sentido, Mauro Cabral vai afirmar que por definição o conceito de transgênero é heterogêneo, pois

designa um conjunto de discursos, práticas, categorias identitárias e, de modo geral, formas de vida reunidas sob sua designação daquilo que tem em comum: uma concepção às vezes materialista e contingente do corpo, da identidade, da expressão de si, do gênero e da sexualidade, como uma rejeição compartilhada da diferença sexual como matriz natural e necessária a subjetivação. (Cabral, 2011, p.1, grifos do autor)

Essa multiplicidade de sujeitos em dispersão está em um campo de batalha com a cisheteronormatividade especialmente guerreando no campo do sentido, da autonomia decisória e da biotecnologia, enlaçando elementos como a carne, o corpo, as próteses, o desejo, as práticas sexuais, o público e o privado, a identidade, a autoexpressão, o autêntico e o ficcional, o reconhecimento e a subversão da diferença sexual (CABRAL, 2011). Para Cabral, enquanto dispositivo biopolítico, a transgeneridade é contingência, historicidade e ironia.

\footnotetext{
7 Méndez usa aqui o termo "travestismo" numa conceituação distinta da travestilidade sul-americana. No Brasil, travesti longe de ser uma prática de vestir-se do sexo oposto é uma identidade de gênero racializada e muito própria de nossa cultura.
} 


\section{CONSIDERAÇÕES FINAIS}

Com este trabalho buscamos discutir o processo de se afirmar enquanto sujeito transgênero tendo em vista as possibilidades tecnológicas e normativas de cada período histórico e cultural, de cada regime de verdade. A atitude de dizer-a-verdade-sobre-si de sujeitos trans é carregada muitas vezes de riscos em uma sociedade estruturalmente transfóbica.

Ao considerar o dizer-a-verdade-sobre-si de sujeitos transgêneros é preciso considerar os modos como o regime de verdade atua sobre eles, ora afirmando sobre suas subjetividades por saberes avalizados e constituição de classes econômicas, e outra pelos modos como individualmente fazem ressoar tais verdades sobre suas experiências de vida levando-os a inventar modos de vivenciá-la.

É preciso pensar como as tecnologias (médicas, de escrita, de comunicação) disponíveis em cada época, bem como as estruturações de verdade sobre gênero são (re)apropriadas. É desse modo, que identificamos a relação da norma com os processos de veridicção que vão produzir as estruturas de poder, hierarquização entre os sujeitos, bem como processos de subjetivação.

\section{REFERÊNCIAS}

CABRAL, Mauro. La paradoja trangénero. 2011. Disponível em: http://www.ciudadaniasexual.org. Acesso em: 2 mai. 2020.

CANGUILHEM, Georges. O normal e o patológico. 6a. ed. Rio de Janeiro: Forense Universitária, 2009.

CHAVES, Leocádia Aparecida. Autobiografias trans em contexto de ditadura: a coragem de dizer. 2018. Disponível em: https://gelbcunb.blogspot.com/2018/06/autobiografias-trans-em-contexto-de.html. Acesso em: 9 abr. 2019.

FOUCAULT, Michel. Microfísica do Poder. Rio de Janeiro: Edições Graal, 1985.

FOUCAULT, Michel. Segurança, território, população: Curso no Collège de France - 1977-1978. São Paulo: Martins Fontes, 2008.

FOUCAULT, Michel. A coragem da verdade: o governo de si e dos outros II - Curso no Collège de France (1983-1984). São Paulo: Editora WMF Martins Fontes, 2011.

JESUS, Jaqueline Gomes de. Notas sobre as travessias da população trans na história. 2018. Disponível em: https://revistacult.uol.com.br/home/uma-nova-pauta-politica/. Acesso em: 4 fev. 2019.

MACHARIA, Keguro. O Quênia queer na lei e na política. In: REA, C.; PARADIS, C. G.; AMANCIO, I. M. S. (org.). Traduzindo a África Queer. Salvador: Devires, 2018. p. 111-128.

MÉNDEZ, Lucas (Raquel) Platero. Trans*exualidades: acompañamiento, factores de salud y recursos educativos. Barcelona: Edicions Bellaterra, 2014.

MOIRA, Amara. O que nos dizem as autobiografiastrans?2018. Disponívelem: https://www.suplementopernambuco. com.br/artigos/2053-o-que-nos-dizem-as-autobiografias-trans.html. Acesso em: 8 abr. 2019.

NERY, João W. Erro de Pessoa: Joana ou João? 1. ed. Rio de Janeiro: Record, 1984.

NERY, João W. Viagem Solitária: Memórias de um Transexual 30 Anos Depois. São Paulo: Leya, 2011.

PRECIADO, Paul. Um apartamento em Urano. 2018. Disponível em: https://resistaorp.blog/2018/07/05/ um-apartamento-em-urano/. Acesso em: 28 abr. 2020. 
SPALDE, Dean. Compliance is gendered: struggling for gender self-determination in a hostile economy. In: CURRAH, P.; JUANG, R. M.; MINTER, S. P. (org.). Transgender rights. Minneapolis - London: University of Minnesota Press, 2000. p. 217-241.

STEPHENS, Elizabeth. Normal. TSQ: Transgender Studies Quarterly, v. 1, n. 1-2, p. 141-145, 2014.

STONE, Sandy. El imperio contraataca. Um manifesto postranexual. In: GOLOFRE, P.; MISSÉ, M. (org.). Políticas Trans: una antología de textos desde los estudios trans norteamericanos. Barcelona - Madrid: Editorial Egales, 2015. p. 31-65.

WARNER, Michael. Fear of the a queer planet: queer politics and social theory. Minneapolis; London: University of Minnesota Press, 2004.

WILCHINS, Riki Anne. ¿Qué cuesta decir la verdad? In: GALOFRE, Pol; MISSÉ, Miquel (org.). Políticas Trans: una antología de textos desde los estudios trans norteamericanos. Barcelona - Madrid: Editorial Egales, 2015. p. 105-116.

WILLIAMS, Cristan. Transgender. TSQ: Transgender Studies Quarterly, v. 1, n. 1-2, p. 232-234, 2014. Disponível em: https://read.dukeupress.edu/tsq/article/1/1-2/232-234/91833. Acesso em: 25 abr. 2020. 